\title{
Comparison of patients with migraine and tension-type headache in terms of somatosensory amplification and health anxiety
}

\author{
Estudo comparativo de pacientes com enxaqueca e cefaleia do tipo tensional em relação \\ à amplificação somatossensorial e à ansiedade associada à saúde
}

Gül Ferda CENGIZ1', Hikmet SACMACl², Tülin AKTÜRK², Yunus HACIMUSALAR ${ }^{1}$

\begin{abstract}
Although it is known that anxiety and depressive disorders frequently accompany migraine and TTH, the role of somatic amplification (SSA) and health anxiety in these diseases is not adequately known. Objective: The aim of this study is to compare SSA and health anxiety in patients with migraine or TTH, and healthy controls and to investigate the relationships between SSA, health anxiety, headache characteristics, anxiety and depressive symptoms. Methods: Fifty-four migraine, 50 TTH patients from the outpatient unit of the neurology department and 53 healthy volunteers were recruited for the study. The somatosensory amplification scale (SSAS), health anxiety inventory, Beck depression (BDI) and anxiety inventory (BAI) were administered to all participants. Results: The SSAS scores were significantly higher in migraineurs compared with the healthy controls. The health anxiety scores were significantly higher in both migraine and TTH groups. The $\mathrm{BDI}$ and BAI scores were also significantly higher in migraine and TTH groups compared with the controls. A significant positive correlation was found between headache frequency and BAI scores, the visual analogue scale scores and SSAS and BDI scores in migraineurs. The SSAS scores were also significantly correlated with the BDI and BAI scores in both of the headache groups. A similar correlation was determined with the health anxiety scores. Conclusions: While patients with migraine and TTH evalute, taking into account the SSA and health anxiety may contribute to the prognosis and treatment of these diseases.
\end{abstract}

Keywords: Migraine disorders; tension-type headache; anxiety; depression.

\section{RESUMO}

Embora se saiba que os distúrbios de ansiedade e depressão frequentemente acompanhem a enxaqueca e a TTH, o papel da amplificação somatossensorial (somatosensory amplification, SSA) e da hipocondria nessas doenças ainda não é bem conhecido. Objetivo: 0 presente estudo faz uma comparação entre pacientes que sofrem de enxaqueca e TTH com um grupo de controle saudável em termos de SSA e hipocondria e investiga a relação entre os achados e as características da cefaleia, a ansiedade e os sintomas depressivos. Métodos: O estudo incluiu 54 pacientes com enxaqueca, 50 pacientes com TTH e 53 voluntários saudáveis que se cadastraram na clínica de neurologia. A escala de amplificação somatossensorial (somatosensory amplification scale, SSAS), o inventário de hipocondria, o Inventário de Depressão de Beck (Beck Depression Inventory, BDI) e o Inventário de Ansiedade de Beck (Beck Anxiety Inventory, BAI) foram aplicados aos participantes. Resultados: Quando comparados com os controles saudáveis, as pontuações da SSAS dos pacientes com enxaqueca foram significativamente maiores, enquanto as pontuações de hipocondria foram significativamente maiores em ambos os grupos de enxaqueca e TTH. As pontuações do BAl e do BDI foram significativamente maiores em ambos os grupos de pacientes que no grupo de controle. No grupo da enxaqueca, foi identificada uma correlação positiva entre frequência de cefaleia e ansiedade, bem como entre a Escala Analógica Visual (EVA), a SSAS e a depressão. Em ambos os grupos de pacientes, a SSA foi correlacionada positivamente com a depressão e a ansiedade, e uma correlação semelhante foi encontrada entre a SSA e a hipocondria. Conclusão: Em avaliações dessas doenças, a hipocondria e a SSA devem ser levadas em consideração, pois se acredita que essa abordagem possa contribuir positivamente para o prognóstico e tratamento da doença.

Palavras-chave: Transtornos da enxaqueca; cefaleia do tipo tensional; ansiedade; depressão.

\footnotetext{
'Bozok Üniversitesi Tıp Fakültesi, Psikiyatri Anabilim Dalı, Yozgat, Turkey;

${ }^{2}$ Bozok Üniversitesi Tıp Fakültesi, Nöroloji Anabilim Dalı, Yozgat, Turkey.

Gül Ferda Cengiz (iD https://orcid.org/0000-0003-0919-5708; Hikmet Saçmacı (iD https://orcid.org/0000-0003-1480-0562; Tülin Aktürk (iD https://orcid.org/0000-0003-1818-1578; Yunus Hacımusalar (iD) https://orcid.org/0000-0002-1777-2707

Correspondence: Gül Ferda Cengiz; Bozok Üniversitesi Tıp Fakültesi, Psikiyatri Anabilim Dalı, Yozgat 66200, Turkey; E-mail: glferda@hotmail.com

Conflict of interest: There is no conflict of interest to declare.
}

Received 21 March 2019; Received in final form 26 April 2019; Accepted 19 June 2019 
Approximately half of the world's population suffer from active headaches ${ }^{1}$, which, despite being regarded as the third most common cause of disability ${ }^{2}$, still remains underdiagnosed and undertreated. Consequently, there is a need for studies providing insight into the pathophysiology of migraine and tension-type headache (TTH), as the most common causes of headache.

Migraine and TTH are often accompanied by psychiatric disorders, the most widely known and extensively studied of which are those involving anxiety and depression ${ }^{3}$. Little is known, however, about the somatic symptoms and health anxiety associated with headaches. The presence of comorbid psychiatric disorders is associated with the progression to chronic migraine ${ }^{4}$ or disability ${ }^{5}$. The early recognition of any comorbid psychiatric disorders and the elucidation of factors affecting these comorbid conditions are important for disease prognosis.

Somatosensory amplification (SSA) refers to the experiencing of normal and harmless sensations as intense and disturbing, and was first described by Barsky ${ }^{6}$. Only one study to date has demonstrated that migraine patients have a tendency to notice bodily sensations to a greater degree ${ }^{5}$, while there have been no studies replicating this finding and comparing it with TTH.

Health anxiety refers to the belief that one has a serious illness, based on a misinterpretation of bodily sensations and a high level of anxiety about health status ${ }^{7}$. There is evidence suggesting a close relationship between increased somatic symptom load and health anxiety ${ }^{8}$ that has raised questions of whether patients with headaches reporting excessive somatic symptoms ${ }^{9,10}$ also have increased health anxiety. To the best of our knowledge, there has been no study to date evaluating SSA and health anxiety in patients with migraine and TTH. The present study aimed to determine whether differences exist between patients with migraine, TTH and healthy controls in terms of SSA and health anxiety; to identify any relationship with symptoms of depression and anxiety if a difference between the groups is identified; and to evaluate whether a relationship exists between the characteristic features of headache, SSA and health anxiety.

\section{METHODS}

\section{Study sample}

The study included 54 patients with migraine and 50 patients with TTH who were admitted to the neurology outpatient clinic of the Research and Application Hospital of the Yozgat Bozok University School of Medicine between May 2018 and February 2019. All patients were evaluated by a neurologist and diagnosed with either migraine or TTH, based on the criteria of the International Classification of Headache Disorders, third edition beta version ${ }^{11}$. The study was approved by the ethics committee of the Bozok University School of Medicine, and all patients participating in the study signed an informed consent form. The inclusion criteria were an age between 18 and 60 years, a diagnosis of migraine or TTH, and willingness to participate in the study. The exclusion criteria were the presence of chronic migraine or TTH, a comorbid neurologic disease, mental retardation, psychiatric comorbidities, chronic disease or malignancy and illiteracy. The control group comprised 53 healthy volunteers with no known neurological or psychiatric illnesses.

Age, sex, educational status and occupation of the participating patients were recorded, and the frequency of headaches was recorded as the number of episodes per month and disease duration in years. A visual analogue scale (VAS) was used to determine the severity of headaches, with a VAS score of 1-3 points indicating mild pain, a score of 4-6 points indicating moderate pain, a score of 7-8 points indicating severe pain, and a score of 9-10 points indicating extremely severe pain ${ }^{12}$.

\section{Scales used in the study}

Somatosensory Amplification Scale (SSAS): This 10-item scale was developed by Barsky et al. ${ }^{13}$ to evaluate the tendency to experience normal bodily sensations as disturbing. The items are scored from 1-5 points. Most of the items are related to a range of disturbing bodily sensations that are not symptoms of disease. The total score on this scale indicates the level of exaggeration of bodily sensations. The validity and reliability of the Turkish version of the scale have been demonstrated ${ }^{14}$.

Health Anxiety Inventory: This is an 18-item self-reported scale developed by Salkovskis et al. ${ }^{15}$ The items are scored from $0-3$, with a higher total score on the scale indicating a high level of health anxiety. A validity and reliability study has been conducted ${ }^{16}$.

Beck Depression Inventory (BDI): This is a 21-item self-reported questionnaire for evaluating the symptoms and severity of depression. Each item is scored from 0-3. The inventory was developed by Beck et al. ${ }^{17}$ and the validity and reliability of the Turkish version have been evaluated ${ }^{18}$.

Beck Anxiety Inventory (BAI): This is a 21-item self-reported questionnaire evaluating the symptoms and severity of anxiety $^{19}$. The scale evaluates the physical, emotional and cognitive aspects of anxiety, and has been demonstrated to be a valid and reliable tool for use in the Turkish population ${ }^{20}$.

\section{Statistical analyses}

Statistical analyses were performed using the Statistical Package for the Social Sciences, version 20. The categorical variables are presented as percentage and counts. The continuous variables are shown as the mean and standard deviation. The variables were investigated using 
visual (histograms, probability plots) and analytical methods (Kolmogorov-Smirnov test) to determine whether or not they were normally distributed. The independent sample t-test was used for comparison between the continuous variables and the chi-square test for the categorical variables. One-way ANOVA was used to compare the SSAS, health anxiety, BDI and BAI scores between the three groups, since parametric test assumptions were met. The Levene test was used to assess the homogeneity of the variances. When an overall significance was observed, pairwise post hoc tests were performed using Tukey's or Tamhane's T2 tests according to homogeneity of variance. The relationships between the variables were evaluated using Pearson's correlation analysis. The level of statistical significance was set at $\mathrm{p}<0.05$.

\section{RESULTS}

The sociodemographic characteristics of the patients with migraine and TTH, as well as the control participants, are presented in Table 1. There was no significant difference between the groups in terms of age or sex $(p>0.05)$. The differences between the patients with migraine and TTH in terms of pain characteristics are presented in Table 2.

The comparison of the SSAS, health anxiety, BAI and BDI scores of the groups is presented in Table 3. Statistically significant differences were found between all scores of all groups. A post hoc analysis showed significantly higher SSAS scores in the migraine group ( $p=0.001)$. While no significant difference was identified between the patients with TTH and the healthy controls $(\mathrm{p}=0.111)$, the SSAS scores did not differ

Table 1. Sociodemographic characteristics of patients with migraine, tension type headache and control groups.

\begin{tabular}{|c|c|c|c|c|}
\hline \multirow[t]{2}{*}{ Variabe } & $\begin{array}{l}\text { Migraine } \\
(n=54)\end{array}$ & $\begin{array}{l}\text { Tension type headacheTH } \\
\qquad(n=50)\end{array}$ & $\begin{array}{l}\text { Healthy controls } \\
\qquad(n=53)\end{array}$ & \multirow[t]{2}{*}{$p$-value } \\
\hline & Number (\%) or mean \pm SD & Number $(\%)$ or mean \pm SD & Number $(\%)$ or mean \pm SD & \\
\hline Age & $37.3 \pm 9.42$ & $35.52 \pm 12.11$ & $36.23 \pm 11.28$ & 0.707 \\
\hline \multicolumn{5}{|l|}{ Sex } \\
\hline Female & $45(83.3 \%)$ & $41(82 \%)$ & $40(75.5 \%)$ & 0.553 \\
\hline Male & $9(16.7 \%)$ & $9(18 \%)$ & $13(24.5 \%)$ & \\
\hline \multicolumn{5}{|l|}{ Marital status } \\
\hline Married & $44(81.5 \%)$ & $34(68 \%)$ & $27(50.9 \%)$ & \\
\hline Single & $9(16.7 \%)$ & $13(26 \%)$ & $25(47.2 \%)$ & \\
\hline Divorced/widow & $1(1.9 \%)$ & $3(6 \%)$ & $1(1.9 \%)$ & \\
\hline \multicolumn{5}{|l|}{ Education } \\
\hline $1-5$ years & $15(27.8 \%)$ & $19(38 \%)$ & $5(9.4 \%)$ & \\
\hline $5-8$ years & $10(18 . \% 5)$ & $7(14 \%)$ & $2(3.8 \%)$ & \\
\hline High school & $13(24.1 \%)$ & $11(22 \%)$ & $7(13.2 \%)$ & \\
\hline Undergraduate & $16(29.6 \%)$ & $13(26 \%)$ & $39(73.6 \%)$ & \\
\hline \multicolumn{5}{|l|}{ Job status } \\
\hline Homemaker & $29(53.7 \%)$ & $26(52 \%)$ & $7(13.2 \%)$ & \\
\hline Employed & $22(40.7 \%)$ & $11(22 \%)$ & $41(77.3 \%)$ & \\
\hline Unemployed & $2(3.7 \%)$ & $2(4 \%)$ & $1(1.9 \%)$ & \\
\hline Student & $1(1.9 \%)$ & $11(22 \%)$ & - & \\
\hline Retired & - & - & $4(7.5 \%)$ & \\
\hline
\end{tabular}

SD: standard deviation; $n$ : number of participants.

Table 2. Comparison of headache characteristics between migraine and tension type headache groups.

\begin{tabular}{|c|c|c|c|c|}
\hline \multirow[t]{2}{*}{ Variable } & $\begin{array}{l}\text { Migraine } \\
(n=54)\end{array}$ & $\begin{array}{l}\text { Tension type headache } \\
\qquad(n=50)\end{array}$ & \multirow[t]{2}{*}{$\mathrm{t}$} & \multirow[t]{2}{*}{$\mathrm{p}$-values } \\
\hline & Mean \pm SD & Mean \pm SD & & \\
\hline Duration of headache, years & $9.99 \pm 7.69$ & $4.96 \pm 6.34$ & 3.605 & $<0.001$ \\
\hline Headache episodes per month & $4.08 \pm 2.93$ & $6.36 \pm 4.05$ & -3.246 & $<0.01$ \\
\hline Visual analogue scale & $7.68 \pm 1.62$ & $7.18 \pm 1.79$ & 1.508 & $>0.05$ \\
\hline
\end{tabular}

SD: standard deviation; $n$ : number of participants; t: independent samples t-test. 
Table 3. Comparison of the somatosensory amplification scale, health anxiety, Beck depression inventory and Beck anxiety inventory scores between groups.

\begin{tabular}{|c|c|c|c|c|c|c|c|c|}
\hline \multirow{2}{*}{ Variables } & \multirow{2}{*}{$\begin{array}{c}\begin{array}{c}\text { Migraine } \\
(n=54)\end{array} \\
\text { Mean } \pm S D\end{array}$} & \multirow{2}{*}{$\begin{array}{c}\begin{array}{c}\text { TTH } \\
(n=50)\end{array} \\
\text { Mean } \pm \text { SD }\end{array}$} & \multirow{2}{*}{ 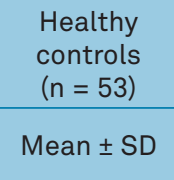 } & \multirow{2}{*}{$\mathrm{F}$} & \multirow{2}{*}{$p$-values } & \multicolumn{3}{|c|}{ Post-hoc test ( $p$ - values) } \\
\hline & & & & & & $\begin{array}{c}\text { Migraine vs. } \\
\text { healthy controls }\end{array}$ & $\begin{array}{l}\text { TTH vs. healthy } \\
\text { controls }\end{array}$ & $\begin{array}{c}\text { Migraine vs. } \\
\text { TTH }\end{array}$ \\
\hline SSAS & $31.16 \pm 8.07$ & $28.20 \pm 8.68$ & $24.79 \pm 8.91$ & 7.424 & 0.001 & 0.001 & 0.111 & 0.185 \\
\hline Health anxiety & $16.77 \pm 7.85$ & $18.60 \pm 7.62$ & $12.88 \pm 4.92$ & 9.220 & $<0.001$ & 0.008 & $<0.001$ & 0.549 \\
\hline $\mathrm{BAl}$ & $17.53 \pm 12.79$ & $21.70 \pm 12.83$ & $7.52 \pm 7.72$ & 21.393 & $<0.001$ & $<0.001$ & $<0.001$ & 0.273 \\
\hline $\mathrm{BDI}$ & $12.14 \pm 10.32$ & $15.54 \pm 9.77$ & $5.24 \pm 5.53$ & 18.437 & $<0.001$ & $<0.001$ & $<0.001$ & 0.242 \\
\hline
\end{tabular}

TTH: tension type headache; SSAS: somatosensory amplification scale; BAI: Beck anxiety inventory; BDI: Beck depression inventory; F: one-way variance analysis (ANOVA).

Table 4. Relationship between headache characteristics and the somatosensory amplification scale, health anxiety, Beck anxiety inventory and Beck depression inventory scores in migraine and tension-type headache group.

\begin{tabular}{|c|c|c|c|c|c|}
\hline Variable & $\begin{array}{c}\text { Correlation } \\
\text { coefficent }\end{array}$ & SSAS & Health anxiety & BAI & BDI \\
\hline \multicolumn{6}{|l|}{ Migraine $(n=54)$} \\
\hline Duration of headache & r & 0.036 & 0.061 & 0.061 & 0.247 \\
\hline Frequency of headache & r & 0.098 & 0.251 & $0.289^{*}$ & 0.116 \\
\hline VAS & r & $0.278^{*}$ & 0.179 & 0.213 & $0.286^{*}$ \\
\hline SSAS & r & & $0.342^{*}$ & $0.491^{\star \star}$ & $0.303^{*}$ \\
\hline Health anxiety & r & & & $0.330^{*}$ & $0.555^{\star *}$ \\
\hline \multicolumn{6}{|l|}{$\mathrm{TTH}(\mathrm{n}=50)$} \\
\hline Duration of headache & r & -0.094 & 0.079 & -0.127 & 0.018 \\
\hline Frequency of headache & r & 0.216 & 0.076 & 0.198 & 0.092 \\
\hline VAS & r & 0.025 & 0.222 & 0.018 & 0.022 \\
\hline SSAS & r & & $0.479^{\star \star}$ & $0.655^{\star \star}$ & $0.518^{\star *}$ \\
\hline Health anxiety & r & & & $0.531^{\star *}$ & $0.458^{* *}$ \\
\hline
\end{tabular}

TTH: tension type headache; SSAS: somatosensory amplification scale; BAI: Beck anxiety inventory; BDI: Beck depression inventory; VAS: visual analogue scale; r: Pearson's correlation coefficient; ${ }^{*} p<0.05 ;{ }^{* *} p<0.01$.

significantly between the patients with migraine and those with TTH $(\mathrm{p}>0.05)$.

A comparison of the health anxiety scores of the different groups identified significantly higher scores in both the migraine and TTH groups when compared with the healthy controls (migraine group $\mathrm{p}=0.008$, TTH group $\mathrm{p}<0.001$ ). The comparison of BAI and BDI scores also showed significantly higher scores in the migraine and TTH groups than in the healthy control group $(\mathrm{p}<0.001)$.

A correlation analysis of the SSAS, health anxiety, BAI and BDI scores and the characteristics of headaches in the migraine patients (Table 4) showed a significant positive correlation between the VAS scores and the SSAS and BDI scores ( $\mathrm{r}=0.278 \mathrm{p}<0.05, \mathrm{r}=0.286 \mathrm{p}<0.05$, respectively). There was also a significant positive correlation between the frequency of pain and the BAI score $(r=0.289, \mathrm{p}<0.05)$. No significant correlation was identified between the variables and the duration of pain. A significant positive correlation was noted between the SSAS score and the BAI and BDI scores $(r=0.491$ $\mathrm{p}<0.01, \mathrm{r}=0.303 \mathrm{p}<0.05$, respectively). The health anxiety score was found to be correlated with the BAI and BDI scores ( $\mathrm{r}=0.330 \mathrm{p}<0.05, \mathrm{r}=0.555 \mathrm{p}<0.01$, respectively). A correlation analysis using the same parameters in patients with TTH showed no significant correlation between headache characteristics and the variables. Similar to that in the migraine group, a significant positive correlation was found between the SSAS score and the BAI and BDI scores of patients with TTH $(r=0.655 \mathrm{p}<0.01, \mathrm{r}=0.518 \mathrm{p}<0.01$, respectively). There was also a significant correlation between the health anxiety score and the BAI and BDI scores $(r=0.531 \mathrm{p}<0.01, \mathrm{r}=0.458$ $\mathrm{p}<0.01$, respectively).

\section{DISCUSSION}

The results of the present study revealed that migraine patients had a higher tendency to be aware of bodily sensations than healthy controls, and that patients with TTH 
were similar to the healthy controls in terms of somatosensory amplification. This finding is consistent with the study by Yavuz et al., who showed similar findings in patients with migraine ${ }^{5}$, although their study included all patients with migraine, and made no differentiation between episodic and chronic migraine. The present study included only patients with episodic migraine to ensure a more homogeneous study group, given that there are important pathophysiological and clinical differences between episodic and chronic migraine ${ }^{20}$.

It has been reported that migraine is often accompanied by such functional somatic syndromes as fibromyalgia, irritable bowel syndrome, chronic fatigue syndrome and back pain ${ }^{9,22}$. The authors attribute this to the common pathophysiological mechanism of central sensitization, and the increased SSA among migraine patients in the present study can be regarded as a reflection of this. Pain modulation in the central nervous system is altered, resulting in increased neuronal excitability and/or decreased inhibitor mechanisms, leading to sensitization. Although it is not known how this system is activated and maintained, genetic predisposition is said to be involved in the more susceptible individuals ${ }^{23}$.

There have been previous studies reporting on the role of repetitive painful stimuli in central sensitization ${ }^{24}$, although the present study found no relationship between SSA and pain frequency. Furthermore, SSAS scores have been found to be lower in patients with TTH, in whom the frequency of pain is higher than in patients with migraine. The SSAS scores were found to be weakly correlated with the severity of pain in the present study. Maizel et al. have also found a relationship between headache severity and somatic symptoms ${ }^{10}$. Another study, conducted on patients with fibromyalgia and chronic fatigue syndrome, found a correlation between somatosensory amplification and pain severity ${ }^{25}$. These individuals may be susceptible to somatic symptoms and, therefore, perceive more intense pain.

Based on the assumption that SSA has three components ( 1 - increased attention to bodily sensations, 2 focus on some of the weaker and infrequent bodily sensations, and 3 - cognitive and emotional reactions to bodily sensations $)^{6}$, migraine patients may focus more on their body sensations and pay increased attention in this regard. According to a theory proposed by Köteles et al. ${ }^{26}$, SSA does not refer solely to the amplification of sensations, but it also reflects increased sensitivity to a threat to bodily integrity. That is, these individuals are hypersensitive to any external threat, which may be considered a type of defense mechanism that allows an organism to survive. This hypersensitivity is an adaptive response in the early periods of life, but loses its adaptive feature over time. ${ }^{26}$ Exposure to trauma or stressful experiences are said to play a role in the development of threat hypersensitivity ${ }^{25}$ and, indeed, studies demonstrating greater traumatic experiences in patients with migraine and TTH than in healthy controls provide evidence of this ${ }^{27,28}$.

One of the most important findings of the study is that health anxiety is higher in both types of headaches than in the healthy controls. To the best of our knowledge, there has been no other study in the literature to date investigating health anxiety in patients with migraine and TTH. Although migraine patients have a higher perception of bodily sensations than patients with TTH, the presence of health anxiety in the two patient groups is an interesting finding. There are also other factors mediating the development of health anxiety, one of which is catastrophic thought, as proposed in the model by Seto et al. ${ }^{29}$. According to this notion, perceived bodily sensations exacerbate and transform into disturbing symptoms with catastrophizing and excessive interpretation. The higher health anxiety scores in patients with TTH without significant SSA may be linked to the tendency of these patients to catastrophize bodily sensations, although the present study did not make use of any scale to evaluate catastrophic interpretations. Further studies involving such evaluations may provide additional data on this subject.

Another finding of the present study was the higher anxiety and depression scores in patients with migraine and TTH than in the healthy controls ${ }^{30,31}$, which is consistent with the findings of previous studies. The presence of common pathophysiological mechanisms associated with migraine and anxiety and depressive disorders ${ }^{32}$, and therapies involving antidepressants $^{33}$ and psychotherapies ${ }^{34}$ proving useful in both conditions, may explain why migraines are often accompanied by psychopathological conditions.

The presence of a strong relationship between SSA and health anxiety, and depression and anxiety, in both groups was one of the most important findings of the present study. Different from the present study, Yavuz et al. ${ }^{5}$ identified a relationship between SSA and anxiety in migraine patients, whereas no relationship was reported between depression and SSA. To the best of our knowledge, the present study is the first to report a relationship between health anxiety, depression and anxiety in headaches.

A relationship was found between BAI scores and the frequency of episodes, and between BDI scores and VAS scores in migraine patients. Studies evaluating the relationship between the frequency and severity of episodes and depression and anxiety have yielded controversial results. In a study of migraine patients, it was found that the coexistence of anxiety and depression was related to the frequency of headache episodes, while anxiety was found to be related to the VAS score $^{35}$. Another study comparing patients with migraine and non-migraine headaches reported a relationship between attack frequency, and anxiety and depression ${ }^{36}$. In another study of migraine patients, severity of headache was found to be correlated with depression and emotional stress, whereas attack frequency was not found to be correlated with the presence of any psychopathology ${ }^{37}$. The differences between 
the results may be attributed to the different sample sizes and methodological differences.

In the TTH group, no relationship was identified between the frequency and severity of episodes and the BDI and BAI scores. There have been studies reporting a relationship between the level of anxiety and the frequency of episodes in patients with chronic $\mathrm{TTH}^{38}$, although these studies have mostly involved patients with chronic TTH. The authors, therefore, consider that future studies evaluating the relationship between the frequency and severity of episodes and various psychopathologies in patients with episodic TTH could fill the gaps in this field.

The present study has some limitations, one of which is its cross-sectional design, as not being designed as a longitudinal study complicates the establishment of a causal relationship. Another limitation is that the scales used in the study are based on the self-reports of the patients. Although self-report forms can be considerably useful in the presence of time constraints, they may fail to determine the general condition of an individual as they reflect on their condition at the time of response. Another characteristic that could be regarded as a limitation is the greater number of females than males in the study. In fact, this reflects the real numbers, as it is well known that headaches are more common in females. Nonetheless, large-scale studies with a larger number of male patients would aid in the generalization of the results of the study.

In conclusion, although the present study identified a high level of health anxiety among patients with both migraine and TTH, the higher level of SSA only in patients with migraine is a finding supporting the central sensitization theory, and the assumption that these two types of headaches have different pathophysiological mechanisms. Health anxiety and SSA were found to be strongly related to anxiety and depression. Addressing patients with migraine and TTH through a multidisciplinary approach, and assessing SSA and health anxiety, may provide a positive contribution to the diagnosis and treatment of these patients. Raising awareness of pain and providing patients with psychoeducation through the identification of catastrophizing thoughts may be useful, ${ }^{29}$ and may perhaps prevent progression to chronic pain. There is a need for prospective studies involving larger samples. The authors believe that testing the use of the SSAS as a tool for the prediction of progression to chronic migraine in studies involving patients with chronic headache may make a significant contribution to the literature, although no such assessment was made in the present study.

\section{References}

1. Stovner L, Hagen K, Jensen R, Katsarava Z, Lipton R, Scher A, et al. The global burden of headache: a documentation of headache prevalence and disability worldwide. Cephalalgia. 2007 Mar;27(3):193-210. https://doi.org/10.1111/j.1468-2982.2007.01288.x

2. Steiner TJ, Birbeck GL, Jensen RH, Katsarava Z, Stovner $\mathrm{LJ}$, Martelletti P. Headache disorders are third cause of disability worldwide. J Headache Pain. 2015;16(1):58. https://doi.org/10.1186/s10194-015-0544-2

3. Hamelsky SW, Lipton RB. Psychiatric comorbidity of migraine. Headache. 2006 Oct;46(9):1327-33. https://doi.org/10.1111/j.1526-4610.2006.00576.x

4. Smitherman TA, Maizels M, Penzien DB. Headache chronification: screening and behavioral management of comorbid depressive and anxiety disorders. Headache. 2008 Jan;48(1):45-50. https://doi.org/10.1111/j.1526-4610.2007.00974.x

5. Yavuz BG, Aydinlar El, Dikmen PY, Incesu C. Association between somatic amplification, anxiety, depression, stress and migraine. J Headache Pain. 2013 Jun;14(1):53. https://doi.org/10.1186/1129-2377-14-53

6. Barsky AJ, Goodson JD, Lane RS, Cleary PD. The amplification of somatic symptoms. Psychosom Med. 1988 Sep-Oct;50(5):510-9. https://doi.org/10.1097/00006842-198809000-00007

7. American Psychiatric Association. Diagnostic and statistical manual of mental disorders (5th ed.). Washington, DC: American Psychiatric Association; 2013.

8. Lee S, Creed FH, Ma YL, Leung CM. Somatic symptom burden and health anxiety in the population and their correlates. J Psychosom Res. 2015 Jan;78(1):71-6. https://doi.org/10.1016/j.jpsychores.2014.11.012
9. Grassini S, Nordin S. Comorbidity in migraine with functional somatic syndromes, psychiatric disorders and inflammatory diseases: a matter of central sensitization? Behav Med. 2017 Apr-Jun;43(2):91-9. https://doi.org/10.1080/08964289.2015.1086721

10. Maizels M, Burchette R. Somatic symptoms in headache patients: the influence of headache diagnosis, frequency, and comorbidity. Headache. 2004 Nov-Dec;44(10):983-93. https://doi.org/10.1111/j.1526-4610.2004.04192.x

11. Headache Classification Committee of the International Headache Society. The international classification of headache disorders, 3rd edition (beta version). Cephalalgia. 2013 Jul;33(9):629-808. https://doi.org/10.1177/0333102413485658

12. Melzack R. The short-form McGill pain questionnaire. Pain. 1987 Aug;30(2):191-7. https://doi.org/10.1016/0304-3959(87)91074-8

13. Barsky AJ, Wyshak G, Klerman GL. The somatosensory amplification scale and its relationship to hypochondriasis. J Psychiatr Res. 1990;24(4):323-34. https://doi.org/10.1016/0022-3956(90)90004-A

14. Güleç H, Sayar K. Reliability and validity of the Turkish form of the Somatosensory Amplification Scale. Psychiatry Clin Neurosci. 2007 Feb;61(1):25-30. https://doi.org/10.1111/j.1440-1819.2007.01606.x

15. Salkovskis PM, Rimes KA, Warwick HM, Clark DM. The Health Anxiety Inventory: development and validation of scales for the measurement of health anxiety and hypochondriasis. Psychol Med. 2002 Jul;32(5):843-53. https://doi.org/10.1017/S0033291702005822

16. Aydemir Ö, Kirpinar I, Sati T, Uykur B, Cengisiz C; Archives of Neuropsychiatry. Reliability and Validity of the Turkish Version of the Health Anxiety Inventory. Noro Psikiyatri Arsivi. 2013 Dec;50(4):32531. https://doi.org/10.4274/npa.y6383 
17. Beck AT, Ward CH, Mendelson M, Mock J, Erbaugh J. An inventory for measuring depression. Arch Gen Psychiatry. 1961 Jun;4(6):561-71. https://doi.org/10.1001/archpsyc.1961.01710120031004

18. Hisli N. A reliability and validity study of Beck Depression Inventory in a university student sample. J Turkish Psychol. 1989;7:3-13.

19. Beck AT, Epstein N, Brown G, Steer RA. An inventory for measuring clinical anxiety: psychometric properties. J Consult Clin Psychol. 1988 Dec;56(6):893-7. https://doi.org/10.1037/0022-006X.56.6.893

20. Ulusoy M, Sahin NH, Erkmen H. Turkish version the Beck Anxiety Inventory: psychometric properties. J Cogn Psychother. 1998;12:2.

21. Aurora SK, Kulthia A, Barrodale PM. Mechanism of chronic migraine. Curr Pain Headache Rep. 2011 Feb;15(1):57-63. https://doi.org/10.1007/s11916-010-0165-z

22. Ashina S, Lipton RB, Bendtsen L, Hajiyeva N, Buse DC, Lyngberg AC, et al. Increased pain sensitivity in migraine and tension-type headache coexistent with low back pain: A crosssectional population study. Eur J Pain. 2018 May;22(5):904-14. https://doi.org/10.1002/ejp.1176

23. Woolf CJ. Pain amplification-A perspective on the how, why, when, and where of central sensitization. J Appl Biobehav Res. 2018;23(2):e12124. https://doi.org/10.1111/jabr.12124

24. Buchgreitz L, Lyngberg AC, Bendtsen L, Jensen R. Frequency of headache is related to sensitization: a population study. Pain. 2006 Jul;123(1-2):19-27. https://doi.org/10.1016/j.pain.2006.01.040

25. Geisser ME, Strader Donnell C, Petzke F, Gracely RH, Clauw DJ, Williams DA. Comorbid somatic symptoms and functional status in patients with fibromyalgia and chronic fatigue syndrome: Sensory amplification as a common mechanism. Psychosomatics. 2008 MayJun;49(3):235-42. https://doi.org/10.1176/appi.psy.49.3.235

26. Köteles F, Witthöft M. Somatosensory amplification: An old construct from a new perspective. J Psychosom Res. 2017 Oct;101:1-9. https://doi.org/10.1016/j.jpsychores.2017.07.011

27. Kucukgoncu S, Yildirim Ornek F, Cabalar M, Bestepe E, Yayla V. Childhood trauma and dissociation in tertiary care patients with migraine and tension type headache: a controlled study. J Psychosom Res. 2014 Jul;77(1):40-4. https://doi.org/10.1016/j.jpsychores.2014.04.007

28. Tietjen GE, Brandes JL, Peterlin BL, Eloff A, Dafer RM, Stein MR, et al. Childhood maltreatment and migraine (part I). Prevalence and adult revictimization: a multicenter headache clinic survey. Headache. 2010 Jan;50(1):20-31. https://doi.org/10.1111/j.1526-4610.2009.01556.x
29. Seto H, Nakao M. Relationships between catastrophic thought, bodily sensations and physical symptoms.

Biopsychosoc Med. 2017 Nov;11(1):28. https://doi.org/10.1186/s13030-017-0110-z

30. Mongini F, Rota E, Deregibus A, Ferrero L, Migliaretti G, Cavallo F, et al. Accompanying symptoms and psychiatric comorbidity in migraine and tension-type headache patients. J Psychosom Res. 2006 Oct;61(4):447-51. https://doi.org/10.1016/j.jpsychores.2006.03.005

31. Beghi E, Bussone G, D’Amico D, Cortelli P, Cevoli S, Manzoni GC, et al. Headache, anxiety and depressive disorders: the HADAS study. J Headache Pain. 2010 Apr;11(2):141-50. https://doi.org/10.1007/s10194-010-0187-2

32. Ferrari MD, Odink J, Tapparelli C, Van Kempen GM, Pennings EJ, Bruyn GW. Serotonin metabolism in migraine. Neurology. 1989 Sep;39(9):1239-42. https://doi.org/10.1212/WNL.39.9.1239

33. Punay NC, Couch JR. Antidepressants in the treatment of migraine headache. Curr Pain Headache Rep. 2003 Feb;7(1):51-4. https://doi.org/10.1007/s11916-003-0010-8

34. Morgan M, Cousins S, Middleton L, Warriner-Gallyer G, Ridsdale L. Patients' experiences of a behavioural intervention for migraine headache: a qualitative study. J Headache Pain. 2015;17(1):16. https://doi.org/10.1186/s10194-016-0601-5

35. Oh K, Cho SJ, Chung YK, Kim JM, Chu MK. Combination of anxiety and depression is associated with an increased headache frequency in migraineurs: a populationbased study. BMC Neurol. 2014 Dec;14(1):238. https://doi.org/10.1186/s12883-014-0238-4

36. Zwart JA, Dyb G, Hagen K, Ødegård KJ, Dahl AA, Bovim $G$, et al. Depression and anxiety disorders associated with headache frequency. The Nord-Trøndelag Health Study. Eur J Neurol. 2003 Mar;10(2):147-52. https://doi.org/10.1046/j.1468-1331.2003.00551.x

37. Magnusson JE, Becker WJ. Migraine frequency and intensity: relationship with disability and psychological factors. Headache. 2003 Nov-Dec;43(10):1049-59. https://doi.org/10.1046/j.1526-4610.2003.03206.x

38. Peñacoba-Puente C, Fernández-de-Las-Peñas C, González-Gutierrez JL, Miangolarra-Page JC, Pareja JA. Interaction between anxiety, depression, quality of life and clinical parameters in chronic tension-type headache. Eur J Pain. 2008 Oct;12(7):886-94. https://doi.org/10.1016/j.ejpain.2007.12.01 